\title{
Thin Film Nanofibrous Composite Membrane for Dead-End Seawater Desalination
}

\author{
Baturalp Yalcinkaya, ${ }^{1}$ Fatma Yalcinkaya, ${ }^{1}$ and Jiri Chaloupek ${ }^{2}$ \\ ${ }^{1}$ Institute for Nanomaterials, Advanced Technologies and Innovation, Technical University of Liberec, Studentská 1402/2, \\ 46117 Liberec, Czech Republic \\ ${ }^{2}$ Department of Nonwoven and Nanofibrous Material, Faculty of Textile, Technical University of Liberec, Studentská 1402/2, \\ 46117 Liberec, Czech Republic
}

Correspondence should be addressed to Baturalp Yalcinkaya; baturalpyalcinkaya@hotmail.com

Received 28 May 2016; Revised 24 July 2016; Accepted 31 July 2016

Academic Editor: Zeeshan Khatri

Copyright (C) 2016 Baturalp Yalcinkaya et al. This is an open access article distributed under the Creative Commons Attribution License, which permits unrestricted use, distribution, and reproduction in any medium, provided the original work is properly cited.

\begin{abstract}
The aim of the study was to prepare a thin film nanofibrous composite membrane utilized for nanofiltration technologies. The composite membrane consists of a three-layer system including a nonwoven part as the supporting material, a nanofibrous scaffold as the porous surface, and an active layer. The nonwoven part and the nanofibrous scaffold were laminated together to improve the mechanical properties of the complete membrane. Active layer formations were done successfully via interfacial polymerization. A filtration test was carried out using solutions of $\mathrm{MgSO}_{4}, \mathrm{NaCl}, \mathrm{Na}_{2} \mathrm{SO}_{4}, \mathrm{CaCl}_{2}$, and real seawater using the dead-end filtration method. The results indicated that the piperazine-based membrane exhibited higher rejection of divalent salt ions (>98\%) with high flux. In addition, the $m$-phenylenediamine-based membrane exhibited higher rejection of divalent and monovalent salt ions ( $>98 \%$ divalent and $>96 \%$ monovalent) with reasonable flux. The desalination of real seawater results showed that thin film nanofibrous composite membranes were able to retain $98 \%$ of salt ions from highly saline seawater without showing any fouling. The electrospun nanofibrous materials proved to be an alternative functional supporting material instead of the polymeric phase-inverted support layer in liquid filtration.
\end{abstract}

\section{Introduction}

Demand for fresh water sources is increasing due to a population explosion in the world. Humans need drinkable water, and groundwater resources are decreasing more than ever before. Many countries are facing serious problems regarding this. Several technological methods such as desalination $[1,2]$ or distillation of seawater $[3,4]$ have given hope to people in areas of water scarcity. Membrane desalination is an effective technology that produces fresh water from brackish water or seawater using nanofiltration (NF) [5] and reverse osmosis (RO) [6] membrane processes.

Conventional NF and RO membranes consist of a considerably thick phase-inverted polymeric support layer and a relatively thin polyamide (PA) active layer by in situ polymerization of an aqueous solution containing di- or polyfunctional amine and organic solutions containing di- or trifunctional carboxylic acid chloride at their interface [7-12]. Recently, an electrospun nanofibrous layer has been prepared as an alternative supporting layer to form a thin PA active layer using electrospinning methods. In this method, the polymer solutions are spun directly onto nonwoven fabrics to prepare the nanofibres $[13,14]$ and a PA active layer is formed over the nanofibrous layer. The final structure is called a thin film nanofibrous composite (TFNC) membrane. One of the greatest advantages of the TFNC membrane is its extremely high permeate flux due to its high surface area and direct channel structure [15-18]. Besides the high flux performance, TFNC membranes have shown excellent rejection in both mono- and divalent salt ions, indiscriminately [19].

Despite the high salt rejection and permeate flux performance of TFNC membranes, the weak mechanical properties of the nanofibrous layer and insufficient adhesion between the nonwoven layer and the nanofibres have become the main 
limitations of the nanofiltration process. In the literature there are various attempts to overcome the mechanical problem of nanofibres [20-22]. Some of the studies have focused on increasing interfibre adhesion to improve the mechanical properties of the entire membrane $[23,24]$. For instance, a mixed solvent system (dimethylformamide (DMF) and $\mathrm{N}$ methyl-pyrrolidinone (NMP)) was used to prepare a solution of polyethersulfone (PES) by Yoon et al. [25]. A PES polymer solution has been electrospun using needle electrospinning. A different solvent mixed system contained solvents with various vapour pressures. Therefore, the nanoweb on the supporting material was still partly wetted because of the high vapour pressure of NMP, and this could lead to adhesion between the fibres. However, the average fibre diameter increased directly proportional to the mechanical strength [16]. In other studies, to increase the strength and integrity of the nonwoven and nanofibrous composite supporting layer, heat and pressure were applied [26]. These above-mentioned methods influenced the morphology of the nanofibrous layer in a negative way (e.g., there is an increase in the fibre diameter or nonfibrous area). Moreover, the needle electrospinning method, which is a small-scale nanofibres production system, used the studies mentioned above. Hence, the commercialization of those nanofilters is improbable.

The primary purpose of the researcher is to prepare a membrane with the best rejection and flux performance in the area of desalination. In the literature, there are many attempts to increase membrane performance by using various kinds of additives in an aqueous or organic phase to obtain a better IP process [27-29]. Petersen reported that, to obtain higher rejection performance in piperazine-based (PIP) membranes, the presence of an acid acceptor was necessary in an aqueous solution. However, this was not the case for $m$-phenylenediamine-based (MPD) membranes [10]. The reaction rate of a PIP solution into the trimesoyl chloride (TMC) solution was rather low and requires a higher concentration of acyl halide along with an acid acceptor to promote the PA active barrier layer. In the case of MPDbased membranes, the high portion of tertiary amine content acts as a built-in acid acceptor. Hermans proved that the use of a tertiary amine base was necessary to obtain a high rejection rate together with surfactants. However, adding each of them separately did not improve the performance [30]. Mansourpanah indicated that adding different kinds of surfactants (anionic, cationic, and nonionic) affects the filtration performance and morphology of the active barrier layer. They reported that an increase in surfactant concentrations in aqueous PIP solutions usually decreases rejection and increases permeate flux with some exceptions [31, 32].

When it comes to desalination technology, the deadend filtration method is usually applied as a pretreatment for reverse osmosis in seawater desalination using a lowpressure membrane such as microfiltration or ultrafiltration $[33,34]$. The polymeric phase-inverted micro- and ultrafiltration membranes have proved themselves to be able to take on this task. However, polymeric phase-inverted membranes tend to show fouling due to their hydrophobic structure. Moreover, most of the common phase-inverted membranes are produced from expensive polymers such as PVDF, PES, or
PSf using highly concentrated polymer solutions via a solvent and nonsolvent exchange system.

Taking into consideration the above information, the objectives of the present work are the following:

(1) To prepare alternative supporting material, which is relatively cheap and applicable to upscale production of liquid filtration or desalination.

(2) To overcome the main issues of nanofibrous membranes (weak mechanical properties) in liquid nanofiltration and prepare the finest possible nanofibrous surface without negatively affecting the morphology of the nanofibres for PA thin active surface.

(3) To desalinate real seawater provided from the Mediterranean Sea using thin film nanofibrous composite membranes under low pressure via dead-end filtration.

In this study, three-layered thin film nanofibrous composite membranes were prepared. The nonwoven and nanofibrous supporting layers were combined using the lamination method by applying heat and pressure. The top PA thin active layer was formed by interfacial polymerization. The characterizations of laminated support layer and prepared thin film nanofibrous composite membrane were done. The long-term filtration performance was evaluated via a deadend filtration cell using mono- and divalent salt solutions. Finally, real seawater filtration was carried out using the deadend filtration cell.

\section{Experimental}

2.1. Materials. The TFNC bottom substrate was a polypropylene/polyethylene $\left(80 / 20,18 \mathrm{~g} / \mathrm{m}^{2}\right)$ bicomponent spunbond nonwoven fabric (Pegatex S BICO) from Pegas Nonwovens s.r.o. (Czech Republic). The solution used to produce the porous nanofibre layer by electrospinning consisted of polyamide 6 (PA6) (BASF B24) dissolved in acetic acid/formic acid. The selective layer of the TFNC membrane was prepared by interfacial polymerization of two immiscible phases on the porous nanofibre layer. Piperazine (PIP) and $m$-phenylenediamine (MPD) were purchased from SigmaAldrich and prepared in deionised water as aqueous phases, while the organic phase was prepared by dissolving trimesoyl chloride (TMC) (Sigma-Aldrich) in hexane at $40^{\circ} \mathrm{C}$. The filtration performance of TFNC membranes was tested using salt solutions containing magnesium sulphate $\left(\mathrm{MgSO}_{4}\right)$, sodium chloride $(\mathrm{NaCl})$, and calcium chloride $\left(\mathrm{CaCl}_{2}\right)$ purchased from Penta s.r.o. (Czech Republic) and sodium sulphate $\left(\mathrm{Na}_{2} \mathrm{SO}_{4}\right)$ purchased from Lachema, Brno (Chemapol). Triethylamine (TEA) was purchased from Sigma-Aldrich. Sodium hydroxides $(\mathrm{NaOH})$ were chosen as acid acceptor materials and Synferol AH 1241 was used as an anionic surfactant.

2.2. Preparation of the Electrospun PA6 Porous Nanofibrous Layer. A solution of polyamide 6 ( $8 \% \mathrm{wt}$.) was dissolved in acetic acid/formic acid at a ratio of $2 / 1$ at $80^{\circ} \mathrm{C}$ for 


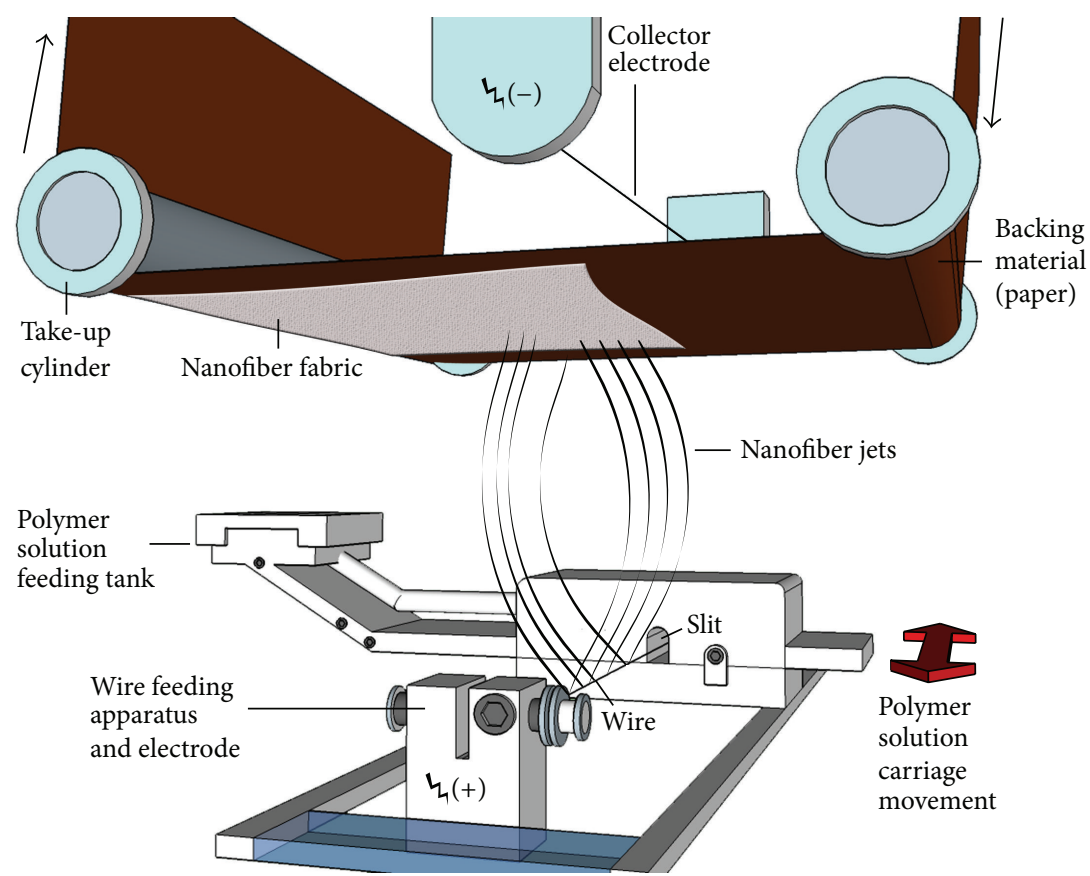

FIgURE 1: Electrospinning of PA6 nanofibres using the Nanospider ${ }^{\mathrm{TM}}$ Production Line NS 1WS500U.

4 hours to produce a nanofibre layer using wire electrode electrospinning equipment (NS 1WS500U, Elmarco s.r.o., Czech Republic). Wire electrospinning is a new technique that uses an electrical force to spin nanofibres from a free surface liquid towards a collector electrode [35] (Figure 1). A solution carriage feeds the polymer solution around a moving stainless steel wire. The speed of the carriage is $245 \mathrm{~mm} / \mathrm{s}$ and the rotation speed of the wire is $40.5 \mathrm{~cm} / \mathrm{h}$. High voltage suppliers are connected to the wire electrode $(55 \mathrm{kV})$ and the collector electrode $(-10 \mathrm{kV})$. When the applied voltage exceeds a critical value, many Taylor cones are created on the surface of the wire. Polymer solution jets move towards the collector, the solvent evaporates, and the PA6 nanofibrous layer is collected on baking paper moving in front of the collector electrode. The speed of the movement of the baking paper is $9 \mathrm{~cm} / \mathrm{min}$.

The distance between the electrodes is $18 \mathrm{~cm}$. The temperature and humidity of input air are set to $23^{\circ} \mathrm{C}$ and $30 \%$ by the air-conditioning system. The volumes of air input and output are 98 and $110 \mathrm{~m}^{3} / \mathrm{h}$, respectively.

2.3. Lamination of Nonwoven and Nanofibrous Materials. Bicomponent spunbond nonwoven and PA6 nanofibrous fabrics were laminated using RPS-Mini fusing lamination equipment (Meyer-Germany). This process was carried out tenuously to avoid damaging the structure of the nanofibres such as the fibre diameter and pore size.

The PA6 nanofibrous layer was put onto PP/PE bicomponent nonwoven fabric and inserted between two Teflon belts moving at $2 \mathrm{~m} / \mathrm{min}$ in the lamination equipment.

The temperature was set at $135^{\circ} \mathrm{C}$ considering the melting point of $\mathrm{PE}\left(120-130^{\circ} \mathrm{C}\right)$. The nanofibrous layer adhered to

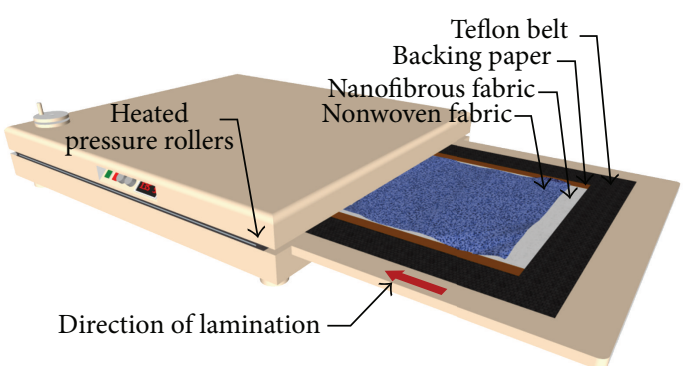

FIGURE 2: Lamination method and equipment.

the nonwoven fabric under a pressure of $15 \mathrm{~N} / \mathrm{cm}$ while the PE fibres partly melted. The resulting product is called the nonwoven-nanofibrous composite (NNC) scaffold (Figure 2).

2.4. Preparation of the Active Barrier Layer. The laminated $\mathrm{PP} / \mathrm{PE}$ bicomponent spunbond nonwoven fabric and the PA6 nanofibrous web were used as supporting material to prepare the TFNC membranes. To form an active barrier layer, interfacial polymerization was carried out using MPD and PIP monomers for an aqueous solution while TMC was used for organic solutions.

To prepare the PIP-based TFNC membranes, TEA $[4.0 \%(\mathrm{w} / \mathrm{v})]$ and $\mathrm{NaOH}[1.0 \%(\mathrm{w} / \mathrm{v})]$ were added to a certain amount of PIP $[2.0 \%(\mathrm{w} / \mathrm{v})]$ aqueous solution while the concentration of the TMC was $[0.2 \%(\mathrm{w} / \mathrm{v})]$. The reaction times selected for the aqueous and organic solutions were $1 \mathrm{~min}$ and $45 \mathrm{sec}$, respectively. The drying time between the solutions was set at $5 \mathrm{~min}$. The temperature and time of curing in the incubator were $110^{\circ} \mathrm{C}$ and $10 \mathrm{~min}$, respectively. 
MPD-based membranes were prepared using an acid acceptor [TEA, 2.0\% (w/v)] and surfactants [anionic liquid, $0.2 \%(\mathrm{w} / \mathrm{v})]$. The selected concentrations of MPD and TMC were $[2.0 \%(\mathrm{w} / \mathrm{v})]$ and $[0.2 \%(\mathrm{w} / \mathrm{v})]$ in aqueous and organic solutions. The IP reaction for the MPD-based membranes was carried out under the same conditions as the drying, curing time, and curing temperature mentioned above for the PIP-based membranes except that the reaction times were different. The selected reaction time for the MPD aqueous solution was $1 \mathrm{~min}$, whereas the reaction time for the organic solution was $30 \mathrm{sec}$.

2.5. Characterization of Enhanced TFNC Membranes. The surface morphologies of enhanced MPD- and PIP-based TFNC membranes were investigated using scanning electron microscopy (Tescan-Vega3 SEM). Attenuated total reflectance Fourier transforms infrared spectroscopy (ATRFTIR) characterization of the MPD- and PIP-based TFNC membrane surfaces was performed with the ATR accessory, using a Nicolet IZ10 (Thermo Fisher Scientific Inc., Waltham, MA). Analysis of samples was carried out by applying the reflection technique using a Germanium crystal. The surface hydrophilicity of the NNC scaffold and MPD- and PIP-based TFNC membranes was evaluated using an optical angle meter (Kruss Drop Shape Analyzer DS4).

2.6. Molecular Weight Cut-Off (MWCO) Test Using Aqueous PEG Solutions. Molecular weight cut-off refers to the lowest molecular weight solute (in daltons) in which $90 \%$ of the solute is retained by the membrane. The MWCO of MPDand PIP-based membranes was evaluated with polyethylene glycol aqueous feed solutions, containing 1000 ppm PEG with different molecular weights (Sigma-Aldrich; Mn: 200, 400, and 600). The permeants and feed solutions were analyzed using a total organic carbon analyzer (direct measurement method, Analytik Jena Multi N/C 2100S, Germany). The filtration performance of PEG solutions was tested using a dead-end filtration cell.

2.7. Liquid Chromatography Analysis. The prepared MPDand PIP-based membranes were used to determine whether residual compounds such as MPD, PIP, TMC, TEA, or surfactants were released from the membranes to the permeation side. Therefore, the membranes were set into a dead-end filtration cell and only pure water was used as a feed solution. The permeate water samples were stored in a vial specifically for liquid analysis. The existence of residual chemicals that could be released from the membrane itself during the pure water filtration experiments was investigated using ABSciex 3200 QTRAP mass spectrometer and Dionex UltiMate 3000 liquid chromatography.

The amount of salt ions $\left(\mathrm{Na}^{+}, \mathrm{Ca}^{+2}, \mathrm{~K}^{+}, \mathrm{Mg}^{+2}, \mathrm{Cl}^{-}, \mathrm{SO}^{-4}\right.$, $\mathrm{NO}^{-2}$, and $\mathrm{NO}^{-3}$ ) in the original feed seawater and filtered seawater was determined through ion chromatography analysis using ICS-90 Dionex.

2.8. Evaluation of Filtration Performance. The dead-end filtration cell was used to investigate the filtration performance
TABLE 1: Properties of the NNC scaffold.

\begin{tabular}{lccc}
\hline $\begin{array}{l}\text { Smallest pore } \\
\text { size }(\mu \mathrm{m})\end{array}$ & $\begin{array}{c}\text { Bubble point } \\
\text { pore size } \\
(\mu \mathrm{m})\end{array}$ & $\begin{array}{c}\text { Mean flow } \\
\text { pore size } \\
(\mu \mathrm{m})\end{array}$ & $\begin{array}{c}\text { Fibre } \\
\text { diameter } \\
(\mathrm{nm})\end{array}$ \\
\hline 0.469 & 1.064 & 0.739 & $126 \pm 29.1$ \\
\hline
\end{tabular}

of enhanced MPD- and PIP-based TFNC membranes. All of the filtration experiments were performed to observe the long-term and fouling performance of the TFNC membranes. The experiments were performed using pure water and salt

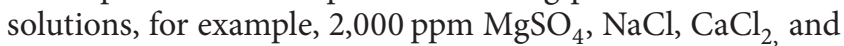
$\mathrm{Na}_{2} \mathrm{SO}_{4}$ solutions, were used as feed water. The rejection performance was calculated by (1), using a conductivity meter:

$$
\text { Rejection }(\%)=\frac{\mathrm{Cf}-\mathrm{Cp}}{\mathrm{Cf}} \times 100
$$

where Cf and $\mathrm{Cp}$ are the conductivity of the feed and permeant concentrations.

\section{Results and Discussion}

3.1. Characteristic of TFNC Membranes. In this study, production of PA6 nanofibres was carried out onto a backing paper substrate using a Nanospider electrospinning device. Subsequently, the PA6 nanofibrous layer was transferred onto a PP/PE spunbond nonwoven fabric by the lamination method. Figure 3 illustrates the top-viewed and crosssectioned SEM image of the TFNC membranes. The average fibre diameter of the top layer of the NNC scaffold was $126 \pm$ $29.1 \mathrm{~nm}$ and the mean flow pore size was $0.739 \mu \mathrm{m}$. Further features of the NNC scaffold are listed in Table 1.

The tensile strength tests of the nonwoven fabric, nanofibrous scaffold, and NNC scaffold were measured individually. The nanofibrous layer showed weak mechanical properties of $4.33 \mathrm{~N} / 25 \mathrm{~mm}$ (machine direction) and $4.12 \mathrm{~N} / 25 \mathrm{~mm}$ (counter-direction), while the tensile strength of the spunbond bicomponent nonwoven fabric was $14.95 \mathrm{~N} / 25 \mathrm{~mm}$ (machine direction) and $6.14 \mathrm{~N} / 25 \mathrm{~mm}$ (counter-direction). When the lamination method was applied, the tensile strength of the NNC scaffold was increased to $29.17 \mathrm{~N} / 25 \mathrm{~mm}$ (machine direction) and $14.42 \mathrm{~N} / 25 \mathrm{~mm}$ (counter-direction). The thicknesses of the nanofibrous scaffold and the spunbond bicomponent nonwoven fabric were $38 \pm 0.5 \mu \mathrm{m}$ and $75 \pm$ $1 \mu \mathrm{m}$, respectively. After lamination of the fabrics, the total scaffold thickness was $105 \pm 5 \mu \mathrm{m}$.

The PIP- and MPD-based TFNC membranes were prepared by adding various additives to the aqueous solutions. The addition of an acid acceptor, a strong base, and anionic surfactants to the aqueous solution had a significant effect on the surface morphology of the PIP- and MPD-based TFNC membranes (Figure 4).

It is evident from the SEM images in Figure 4 that the fibrous pattern of the nanofibrous layer disappeared and formed a typical ridge and valley PA structure on the NNC scaffold. The surface structures of the MPD-based 


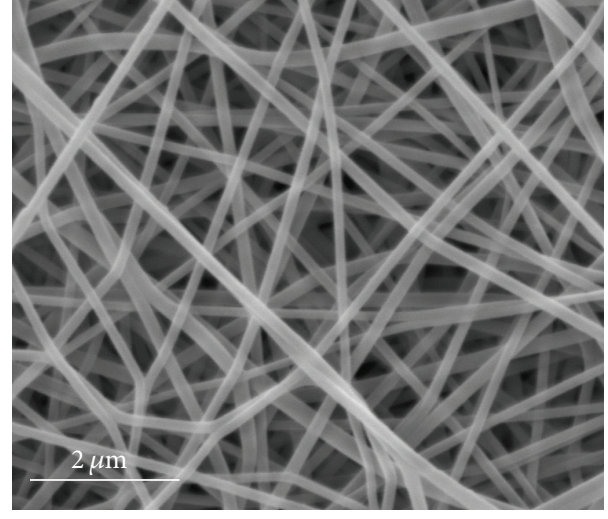

(a)

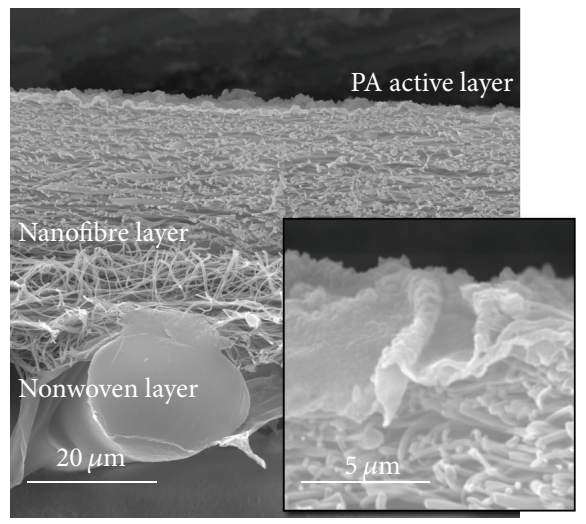

(b)

FIGURE 3: SEM images of (a) top view (nanofibres) and (b) cross-sectioned TFNC membranes.

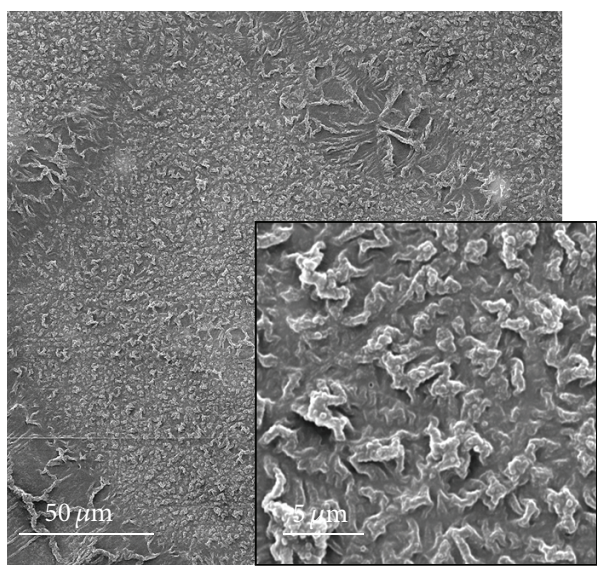

(a)

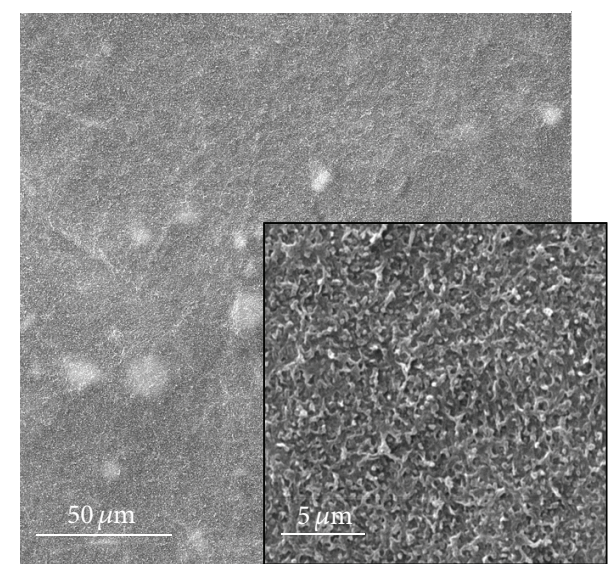

(b)

Figure 4: Surface images of (a) PIP-based membranes which were prepared TEA+NaOH and (b) MPD-based membranes which were prepared TEA+Synferol AH.

membranes prepared with the anionic liquid were smooth and homogenous according to the PIP-based membranes. The morphological difference of the MPD- and PIP-based membranes is mainly due to the difference in the chemical structure of the monomers.

The FTIR spectra of the obtained PIP-based PA active layers on the NNC scaffold are shown in Figure 5. The strong and broad signals around the wavelength of $3,405 \mathrm{~cm}^{-1}$ were observed with the addition of $\mathrm{NaOH}$, which was assigned to the carboxylic acid group or the hydroxyl group on the surface of the active layer. However, for the membranes coated with MPD-based active layers, the same bond seems weaker. A strong band at $1,620 \mathrm{~cm}^{-1}$ is an indicator of the $\mathrm{C}=\mathrm{O}$ bond of an amide functional group for both membranes.

The FTIR spectra of the prepared MPD-based PA active layers on the NNC scaffold are also given in Figure 5. The characteristic properties of the MPD-based membranes were seen at $1,650 \mathrm{~cm}^{-1}$ and $1,550 \mathrm{~cm}^{-1}$, which are represented by the $\mathrm{C}=\mathrm{C}$ bond of the phenyl ring and amide II, respectively. The $\mathrm{C}-\mathrm{H}$ stretching region for the anionic liquid (Synferol AH) can be observed from the medium peaks at $2,956 \mathrm{~cm}^{-1}$ (asymmetric $\mathrm{CH}_{3}$ ), 2,923 $\mathrm{cm}^{-1}$ (asymmetric $\mathrm{CH}_{2}$ ), and $2,854 \mathrm{~cm}^{-1}$ (symmetric $\mathrm{CH}_{3}$ ). The other peaks observed after $1,000 \mathrm{~cm}^{-1}$ indicate $\mathrm{C}-\mathrm{H}$ bonds in aromatics groups.

The reaction of both MPD (Figure 6) and PIP (Figure 7) monomers with TMC led to the successful formation of a dense layer on the NNC scaffold.

The surface hydrophilicity of the prepared PIP- and MPD-based TFNC membranes is given in Table 2.

The NNC scaffold showed slightly hydrophilic behaviour, while the membranes with the active barrier layer showed more hydrophilic behaviour than the NNC scaffold. The measurement of contact angles of the PIP-based membranes showed superhydrophilic behaviour with the existence of acid acceptors (TEA, $\mathrm{NaOH}$ ). The measurement of the contact angle of the MPD-based membranes demonstrated that the addition of an acid acceptor and an ionic liquid to the aqueous solution has a significant effect on the surface hydrophilicity of the active layer. 


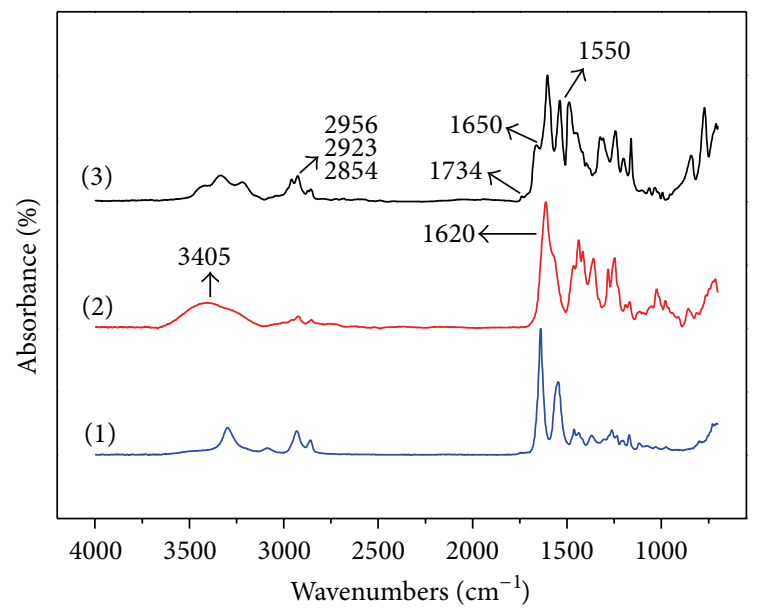

- MPD+TEA+Synferol AH-based layer (3)

- PIP+TEA+NaOH-based layer (2)

- PA nanofibers layer (1)

FIGURE 5: ATR-FTIR of the NNC scaffold (1) and PIP-based (2) and MPD-based (3) membranes.

TABLE 2: Contact angle properties of NNC and TFNC membranes (specified with reaction time).

\begin{tabular}{lcc}
\hline Membranes & $\begin{array}{c}\text { Contact } \\
\text { angle }\end{array}$ & Images of water droplet \\
\hline NNC scaffolds & $62.7 \pm 2.74$ \\
\hline $\begin{array}{l}\text { PIP+TEA+NaOH+TMC } \\
(1 \mathrm{~min}+45 \mathrm{sec})\end{array}$ & 0 \\
\hline $\begin{array}{l}\text { MPD+TEA+Synf+TMC } \\
(1 \mathrm{~min}+30 \mathrm{sec})\end{array}$ & $21 \pm 1.64$ \\
\end{tabular}

3.2. Determination of the Molecular Weight Cut-Off of the TFNC Membranes. The filtration of an aqueous PEG solution with different molecular weights was carried out using deadend filtration to determine the MWCO of the TFNC membrane. Table 3 gives the PEG rejection values of the PIP-based TFNC membrane prepared using TEA $+\mathrm{NaOH}$ as an additive and the MPD-based TFNC membrane prepared using TEA + Synferol AH as an additive. 1000 ppm PEG 200, 400, and 600 solutions were used as the test samples during the MWCO tests.

It was found that the MWCO of the PIP+TEA+NaOHbased membrane was $400 \mathrm{Da}$ (the rejection rate was $91.1 \%$ ). The average solution diameter of PEG- 400 was $1.8 \mathrm{~nm}$, which means that the effective pore size of the PIP+TEA+NaOHbased membrane was around $1.8 \mathrm{~nm}$. The MPD+TEA+SyAH-based membrane showed a high PEG-200 rejection rate $(97.3 \%)$. The average solution diameter of PEG-200
TABLE 3: The rejection values of the TFNC membranes using PEG feed solutions.

\begin{tabular}{lccc}
\hline Membranes & PEG-200 & PEG-400 & PEG-600 \\
\hline PIP+TEA+NaOH & $61.5 \%$ & $91.1 \%$ & 98.9 \\
MPD+TEA+Sy-AH & $97.3 \%$ & $98.9 \%$ & 99.6 \\
\hline
\end{tabular}

TABle 4: Properties of the salt used for the feed solutions.

\begin{tabular}{lccc}
\hline Type of salt & $\begin{array}{c}\text { Conductivity } \\
(\mathrm{mS} / \mathrm{cm})\end{array}$ & $\mathrm{pH}$ & Parts per million (ppm) \\
\hline $\mathrm{MgSO}_{4}$ & 2.21 & 5.59 & 2,000 \\
$\mathrm{Na}_{2} \mathrm{SO}_{4}$ & 5.74 & 6.87 & 2,000 \\
$\mathrm{NaCl}$ & 3.52 & 6.15 & 2,000 \\
$\mathrm{CaCl}_{2}$ & 3.62 & 5.75 & 2,000 \\
\hline
\end{tabular}

was $1.3 \mathrm{~nm}(200 \mathrm{Da})$, which means that the effective pore size of the MPD+TEA+Sy-AH-based membrane was less than $1.3 \mathrm{~nm}$ [36]. The TOC analysis showed that the $\mathrm{PIP}+\mathrm{TEA}+\mathrm{NaOH}$-based membrane was able to retain compounds with a maximum average molecular weight of $400 \mathrm{~g} / \mathrm{mol}$. On the other hand, the MPD+TEA+Sy-AH-based membrane was able to retain a compound with a molecular weight of less than $200 \mathrm{~g} / \mathrm{mol}$.

3.3. Filtration Performance of TFNC Membranes. The filtration processes in the extended period were carried out using a $\mathrm{PIP}+\mathrm{TEA}+\mathrm{NaOH}$-based membrane. First, the filtration process was carried out using distilled water to determine the pure water permeate flux and level of compaction of the membrane (Figure 8).

In the early filtration stage of all of the membranes, determination of the pure water flux is necessary in order for the membranes to reach a steady state. In this study, transmembrane pressure was applied to all of the prepared membranes for compaction. Once the membranes reach a steady state using pure water, the filtration process was carried out for the feed solutions. Figure 8 shows the pure water flux of PIP+TEA $+\mathrm{NaOH}$-based membranes for 24 hours. The filtration of the pure water flux began with $78.5 \mathrm{~L} \mathrm{~m}^{-2} \mathrm{~h}^{-1}$ and was then decreased to 75.9 and $74.7 \mathrm{~L} \mathrm{~m}^{-2} \mathrm{~h}^{-1}$. Stable flux averaging $73.5 \mathrm{~L} \mathrm{~m}^{-2} \mathrm{~h}^{-1}$ was obtained after 6 hours. The differences between the steady state and the third-hour flux were not so significant $\left(1.2 \mathrm{~L} \mathrm{~m}^{-2} \mathrm{~h}^{-1}\right)$. It is also seen from Figure 8 that the amount of compaction on the PIP-based membranes was almost negligible.

After the steady state of the PIP+TEA+NaOH-based membrane was determined and attained using pure water, feed solution experiments were carried out for an extended period. Four kinds of salts, that is, $\mathrm{MgSO}_{4}, \mathrm{NaCl}, \mathrm{CaCl}_{2}$, and $\mathrm{Na}_{2} \mathrm{SO}_{4}$, were chosen for the feed solution. The properties of the salt solutions are given in Table 4 and the filtration performances of the four kinds of solution are illustrated in Figure 9.

The flux and rejection performance are shown for the filtration of feed solutions in all of the graphs in Figure 9. 


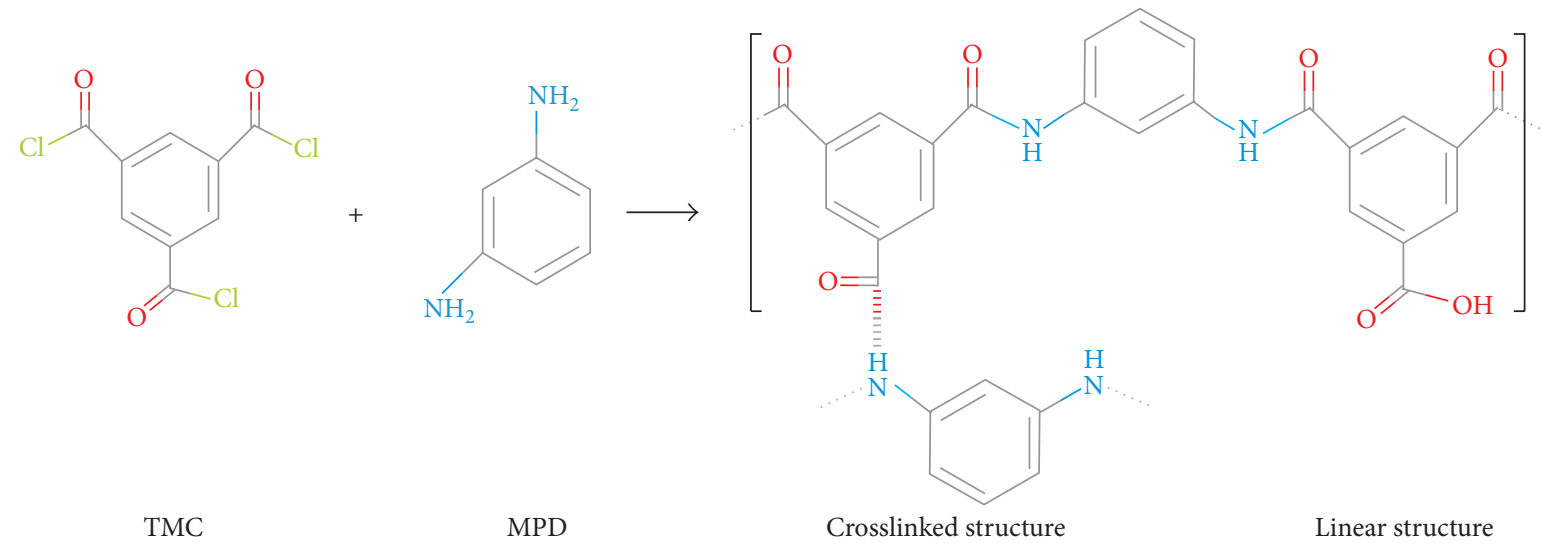

Figure 6: An aromatic polyamide formed with trimesoyl chloride and $m$-phenylenediamine.

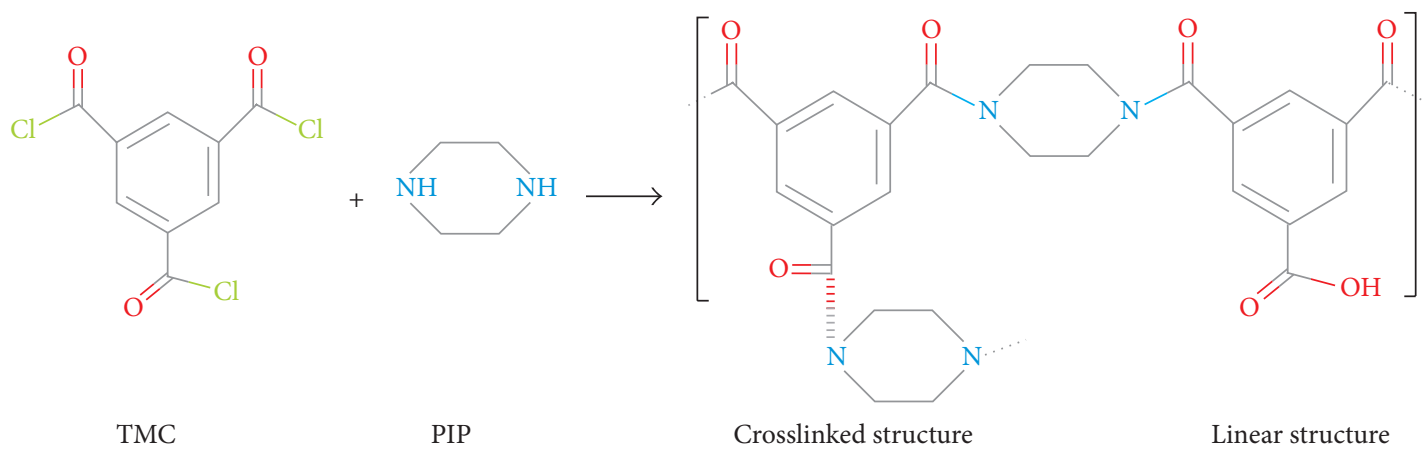

FIGURE 7: Reaction of trimesoyl chloride and piperazine to aliphatic PA.

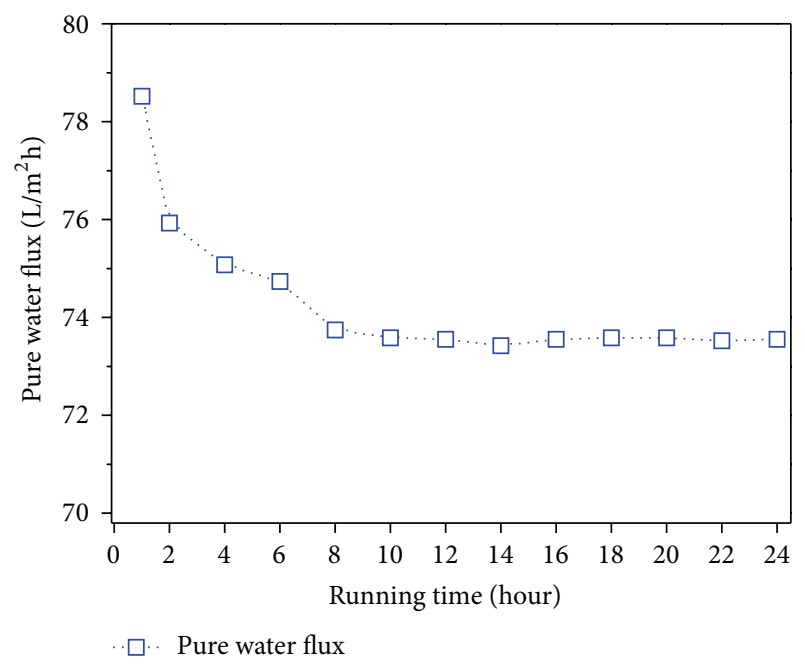

FIGURE 8: Observation of the filtration process for an extended period of $\mathrm{PIP}+\mathrm{TEA}+\mathrm{NaOH}$ membrane using pure water at $4.8 \mathrm{bar}$.

In Figure 9(b), the flux performance showed a decreasing trend, which means that the PIP+TEA+NaOH-based membrane showed slightly fouling behaviour during the filtration of the $\mathrm{Na}_{2} \mathrm{SO}_{4}$ feed solution. Eventually, the
$\mathrm{PIP}+\mathrm{TEA}+\mathrm{NaOH}$-based membrane showed a high rejection performance for divalent salts. Inherently, the retained monovalent salt ratios were low.

The MPD+TEA+Sy-AH-based membrane used for the pure water filtration over an extended period is shown in Figure 10.

The MPD+TEA+Sy-AH-based membrane began with considerably high pure water flux; after a while the pure water flux becomes stable and reaches a steady state. The pure water flux began around $31.2 \mathrm{~L} \mathrm{~m}^{-2} \mathrm{~h}^{-1}$ and then reached a steady state at $22.3 \mathrm{~L} \mathrm{~m}^{-2} \mathrm{~h}^{-1}$ after 6 hours. The membrane compaction is crucial for the NF and RO membranes and depends on the applied pressure and type of membrane [37, 38]. Flux performance can drop significantly, especially in reverse osmosis membranes [39]. Figures 8 and 10 show that the compaction rate of the TFNC membranes is substantially low due to the advantages of the fibrous structure of the supporting layer.

The filtration experiments of different salt-based feed solutions for the MPD+TEA+Sy-AH-based membrane are given in Figure 11. The rejection rates of divalent salts were higher than $98 \%$ and were around $96-97 \%$ for monovalent salts. The flux performance of the MPD+TEA+Sy-AH-based membrane showed a slightly decreasing trend. This may be explained by the concentration polarization due to the use of a dead-end filtration cell. 


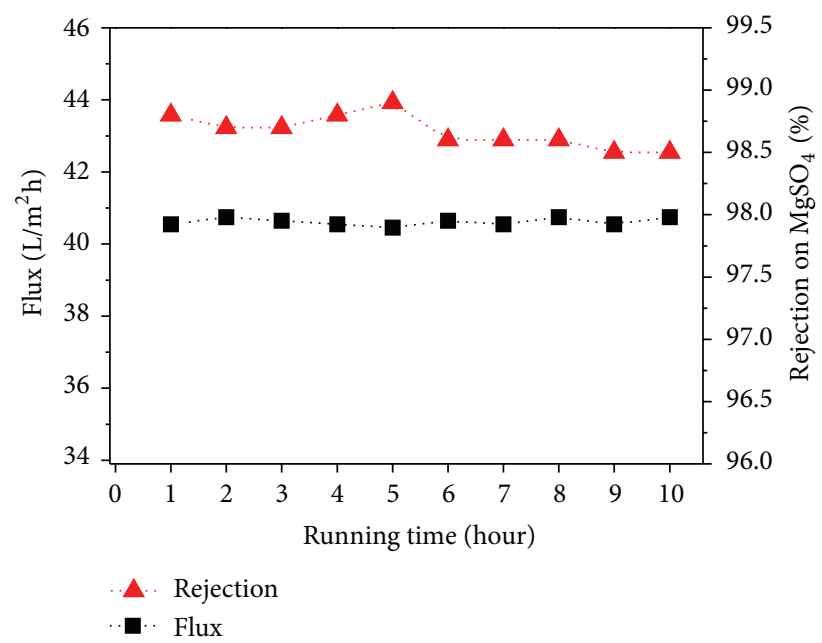

(a)

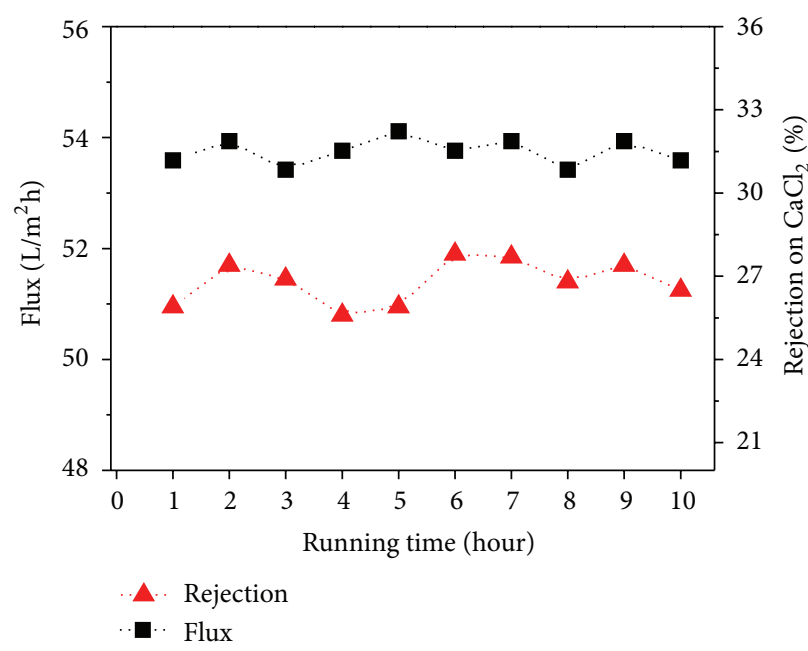

(c)

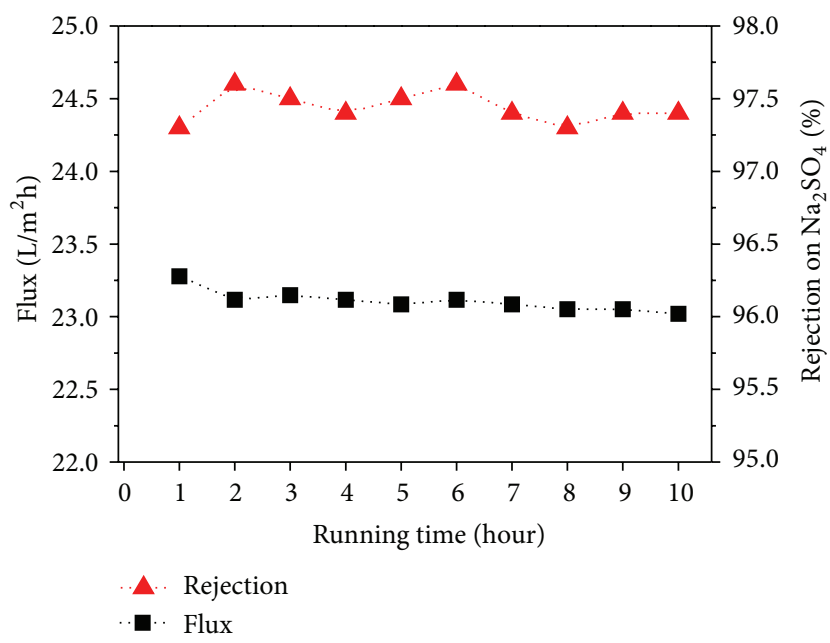

(b)

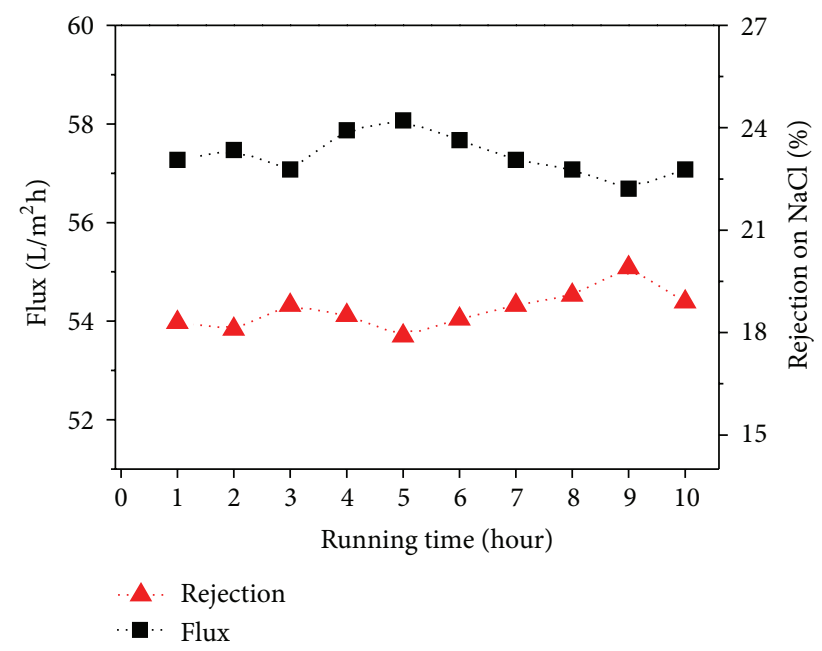

(d)

Figure 9: Extended filtration of (a) $\mathrm{MgSO}_{4}$, (b) $\mathrm{Na}_{2} \mathrm{SO}_{4}$, (c) $\mathrm{CaCl}_{2}$, and (d) $\mathrm{NaCl}$ feed solutions at 2,000 ppm and 4.8 bar using a dead-end cell.

A specific amount of feed water was used in each experiment, and the circulation of feed water was impossible in the dead-end filtration system. As the water molecules diffuse through the TFNC membrane, the salt ion is retained and the concentration of feed water continuously increases. Due to the fact that the ratio of salt ions increased rapidly, concentrated feed solutions accumulate on the surface of the membrane and lead to salt leakage or fouling. Moreover, the osmotic pressure of the feed water increases proportionally to the concentration of the feed solution. For this reason, the flux of feed water tended to decrease during filtration using the MPD-based membranes.

3.4. Analysis of Real Seawater Filtration. The desalination of seawater using membrane technology is a promising technique, which essentially requires more than one step to produce drinkable water such as prefiltration, microfiltration, and softening. The results of ion-exchange chromatography analysis and conductivity measurements show that the amount of the main dissolved salt ions and the conductivity of the seawater were extremely high for the NF membrane filtration process (Table 5).

The primarily filtration experiment was carried out using $\mathrm{PIP}+\mathrm{TEA}+\mathrm{NaOH}-$ and MPD+TEA+Sy-AH-based membranes by measuring the conductivity of the permeate water only (Figure 12).

The results in Figure 12 show that the conductivity value of permeate water dropped from $53.2 \mathrm{mS} / \mathrm{cm}$ to $47 \mathrm{mS} / \mathrm{cm}$ and $38 \mathrm{mS} / \mathrm{cm}$, respectively, while the flux performance was $24.6 \mathrm{~L} \mathrm{~m}^{-2} \mathrm{~h}^{-1}$ and $0.65 \mathrm{~L} \mathrm{~m}^{-2} \mathrm{~h}^{-1}$, respectively. It is clear that the PIP- and MPD-based membranes remained incapable of retaining an excessive amount of salt ions in the seawater all at once. For this reason, the same feed seawater was circulated and was used more than once while the same membrane was fixed on the dead-end cell.

The filtration experiment of circulated seawater started with the PIP-based membranes and was repeated six times. Subsequently, the same permeate water was used 


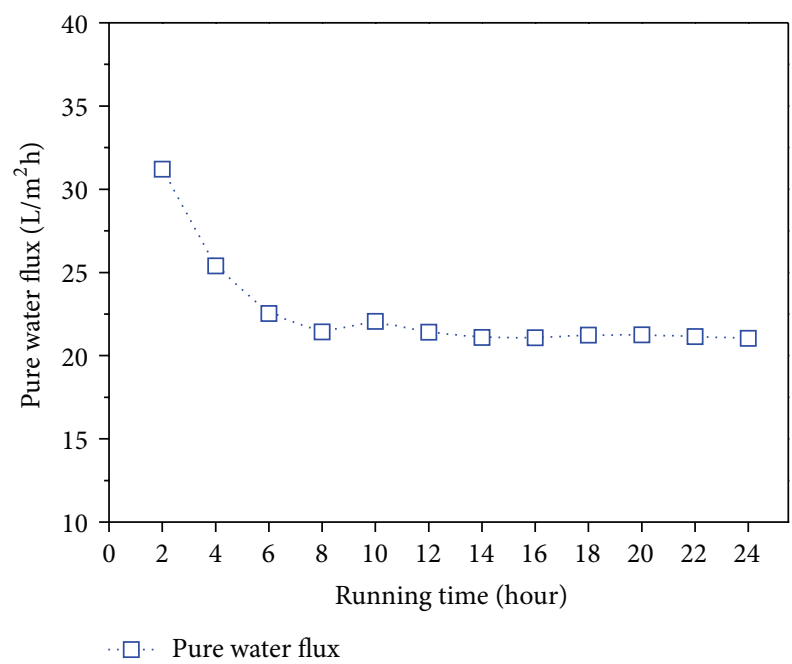

FIGURE 10: Observation of the filtration process of MPD+TEA+Sy$\mathrm{AH}$ membrane for an extended period using pure water at $4.8 \mathrm{bar}$.

TABLe 5: The main dissolved ions in a Mediterranean seawater sample.

\begin{tabular}{lc}
\hline Cations & $\mathrm{mg} / \mathrm{L}$ \\
\hline $\mathrm{Na}^{+}$ & 11,741 \\
$\mathrm{Mg}^{+2}$ & 1,447 \\
$\mathrm{Ca}^{+2}$ & 433 \\
$\mathrm{~K}^{+}$ & 411 \\
\hline Anions & $\mathrm{mg} / \mathrm{L}$ \\
\hline $\mathrm{Cl}^{-}$ & 21,384 \\
$\mathrm{SO}_{4}{ }^{-2}$ & 2,357 \\
$\mathrm{NO}_{2}{ }^{-}$ & $<100$ \\
$\mathrm{NO}_{3}{ }^{-}$ & $<100$ \\
\hline $\mathrm{Conductivity} \mathrm{of} \mathrm{seawater}$ & $53.2 \mathrm{~ms} / \mathrm{cm}$ \\
\hline
\end{tabular}

as feed water using the MPD-based membranes and was repeated four times (Figure 13). The flux performance of the PIP+TEA+NaOH-based membranes in the filtration of seawater was higher compared to the MPD+TEA+Sy-AHbased membranes. Moreover, the flux performance of PIPbased membranes increased after each filtration process, while the conductivity of the feed seawater decreased. The conductivity of the feed seawater remained stable after the fifth $(32.5 \mathrm{mS} / \mathrm{cm})$ and sixth $(32.0 \mathrm{mS} / \mathrm{cm})$ filtration (Figure 13(a)). It was understood that after four filtration cycles using the PIP-based membranes there was none or only trace amounts of divalent salt ions in the feed seawater. The rate of recovery was more than $95 \%$ at the end of the filtration processes of seawater using the PIP-based membrane.

Further filtration was continued with MPD+TEA+Sy$\mathrm{AH}$-based membrane using prefiltered feed seawater, which had a conductivity of $32.0 \mathrm{mS} / \mathrm{cm}$ (Figure 13(b)). In the first attempt of filtration, the conductivity dropped to $20 \mathrm{mS} / \mathrm{cm}$ while the flux performance was $0.935 \mathrm{~L} \mathrm{~m}^{-2} \mathrm{~h}^{-1}$, which was slightly higher than shown in Figure 12. During the second filtration of the feed seawater, the conductivity decreased to
TABLE 6: Amount of ions in the filtered seawater sample [permeant (4.) in Figure 13(b)].

\begin{tabular}{lc}
\hline Cations & $\mathrm{mg} / \mathrm{L}$ \\
\hline $\mathrm{Na}^{+}$ & 219 \\
$\mathrm{Mg}^{+2}$ & 1.8 \\
$\mathrm{Ca}^{+2}$ & 9.4 \\
$\mathrm{~K}^{+}$ & 8.6 \\
\hline Anions & $\mathrm{mg} / \mathrm{L}$ \\
\hline $\mathrm{Cl}^{-}$ & 341 \\
$\mathrm{SO}_{4}{ }^{-2}$ & 4.2 \\
$\mathrm{NO}_{2}{ }^{-}$ & $<10$ \\
$\mathrm{NO}_{3}{ }^{-}$ & $<10$ \\
\hline $\mathrm{Conductivity} \mathrm{of} \mathrm{seawater}$ & $585.1 \mu \mathrm{S} / \mathrm{cm}$ \\
\hline
\end{tabular}

$10.5 \mathrm{mS} / \mathrm{cm}$ while the flux performance was more or less the same $\left(0.965 \mathrm{~L} \mathrm{~m}^{-2} \mathrm{~h}^{-1}\right)$.

After the fourth attempt at MPD-based filtration, the conductivity of the obtained permeate water was $585.1 \mu \mathrm{S} / \mathrm{cm}$ with increased flux $\left(1.12 \mathrm{~L} \mathrm{~m}^{-2} \mathrm{~h}^{-1}\right)$, which means that approximately $98.9 \%$ of the salt ions were retained from the seawater using TFNC membranes by dead-end filtration. The final recovery rate was around $75 \%$ at the end of the seawater filtration process using the MPD-based membrane.

The analysis of ion-exchange chromatography was carried out again, and the amounts of salt ions in the filtered water are given in Table 6.

It is clear from Figure 13 that the rejection ratio of salt ions from seawater was dependent on the number of repetitions of the circulated feed seawater using the dead-end filtration method. We firmly believe that there was a chance to retain the rest of the salt ions from the obtained seawater permeants by increasing the circulation time. However, the flux performance of the MPD-based membranes dropped extremely. It was not reasonable to proceed with the filtration of seawater experiment using a dead-end filtration cell and so we limited the circulation times of the feed seawater to four using the MPD-based membrane.

Another advantage of TFNC membranes was revealed by liquid chromatography analysis of permeate water. The results of the analysis showed that the amount of the residual chemical, which was maybe released from the membrane itself, was not observed except for a trace amount of TEA $(0.1 \mathrm{mg} / \mathrm{L}$ after 5 hours of pure water filtration).

\section{Conclusion}

In this study, not only the flux performances but also the rejection performances of MPD- and PIP-based membranes were significantly high using an acid acceptor and surfactants. The addition of TEA as an acid acceptor is necessary for the formation of poly(piperazine amide). The presence of TEA increased the reaction rate of the PIP monomer to the TMC monomers. A strong base $(\mathrm{NaOH})$ was added as a second additive to the aqueous solution and a poly(piperazine amide) active layer formed onto the NNC scaffold. The highest divalent rejection performance 


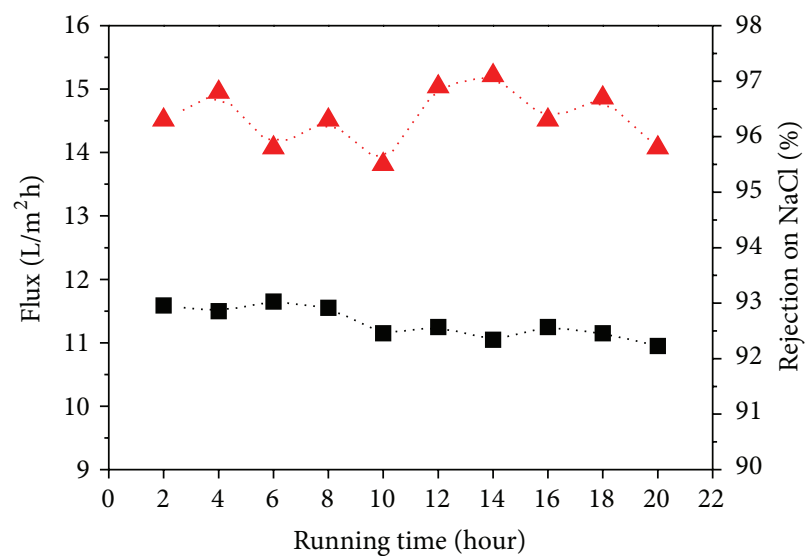

... Rejection

- Flux

(a)

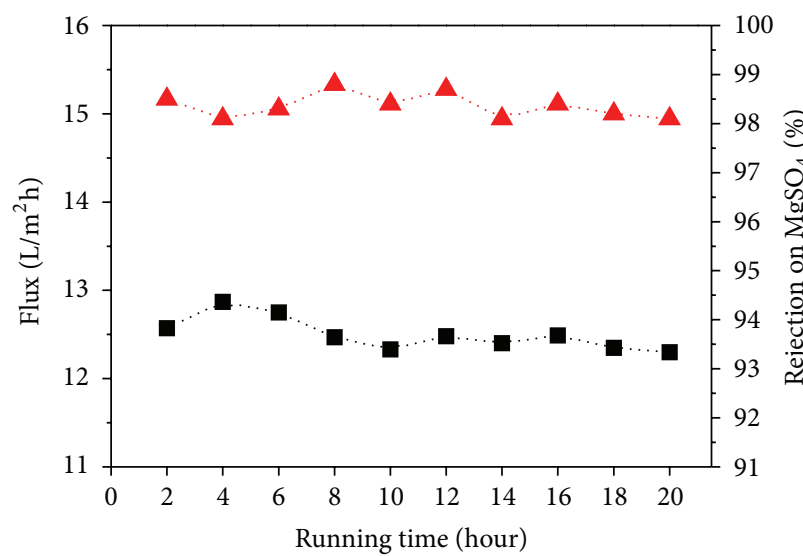

A. Rejection

- . Flux

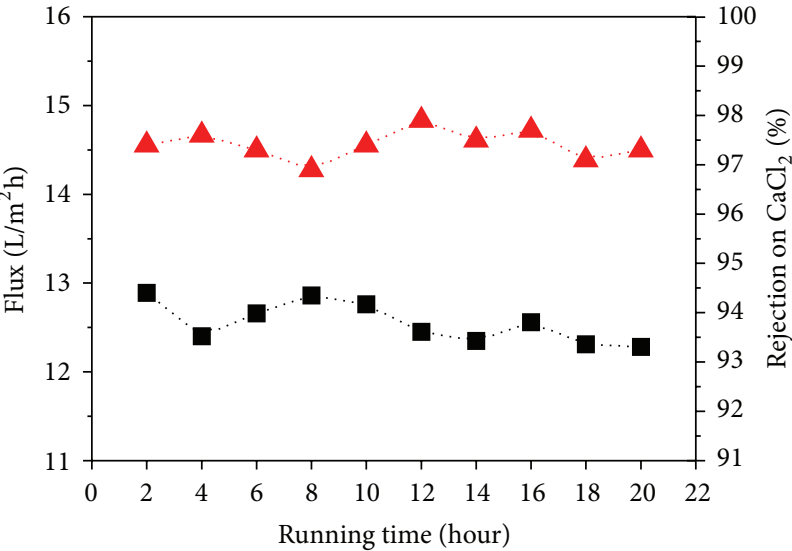

A. Rejection

- . Flux

(b)

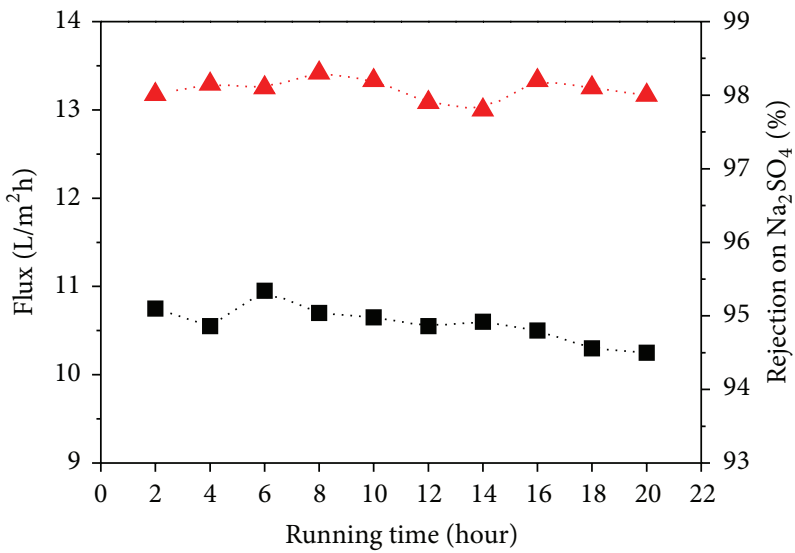

A. Rejection

-. Flux

(c)

(d)

Figure 11: Extended filtration of (a) $\mathrm{NaCl}$, (b) $\mathrm{CaCl}_{2}$, (c) $\mathrm{MgSO}_{4}$, and (d) $\mathrm{Na}_{2} \mathrm{SO}_{4}$ feed solutions at 2,000 ppm and 4.8 bar using a dead-end cell.

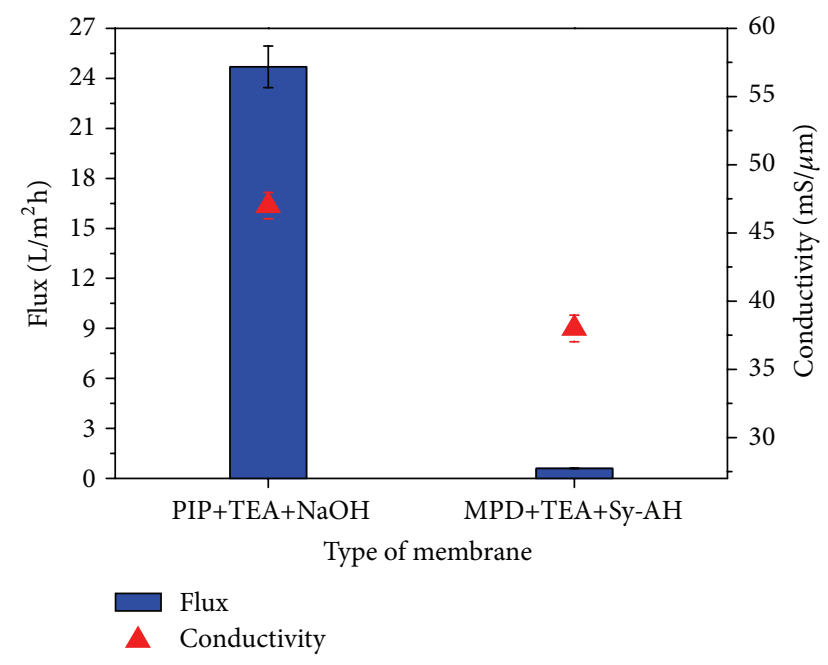

FIGURE 12: Filtration experiment of seawater using different membranes and a dead-end cell at 4.8 bar. was obtained using the PIP+TEA+NaOH-based membrane, which was on average $98.8 \% \mathrm{MgSO}_{4}$ and $97.4 \% \mathrm{Na}_{2} \mathrm{SO}_{4}$. Even though the effect of the dead-end filtration method proved to be a disadvantage, the pure water flux and permeate flux of $\mathrm{PIP}+\mathrm{TEA}+\mathrm{NaOH}$-based membranes were high, that is, $73.5 \mathrm{~L} \mathrm{~m}^{-2} \mathrm{~h}^{-1}$ and $40.5 \mathrm{~L} \mathrm{~m}^{-2} \mathrm{~h}^{-1}$, respectively. The MPDbased membrane showed high flux and rejection performance with the addition of an anionic liquid and TEA. The highest monovalent rejection performance was recorded with the MPD+TEA+Sy-AH-based membrane, which had an average of $97.4 \% \mathrm{CaCl}_{2}$ and $96.3 \% \mathrm{NaCl}$. The pure water flux and permeate flux of the MPD+TEA+Sy-AHbased membrane were high, that is, $22.5 \mathrm{~L} \mathrm{~m}^{-2} \mathrm{~h}^{-1}$ and 12.5 $\mathrm{L} \mathrm{m}^{-2} \mathrm{~h}^{-1}$, respectively.

The filtration experiments of the real seawater indicated that the TFNC membranes were not able to retain a sufficient amount of salt ions at the first attempt. For this reason, the combination of circulated feed seawater was used to retain 


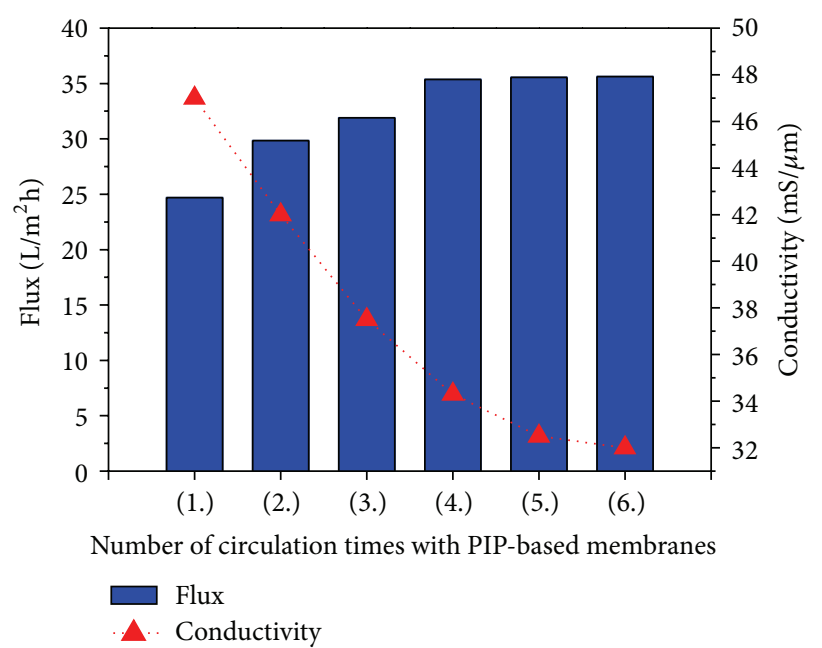

(a)

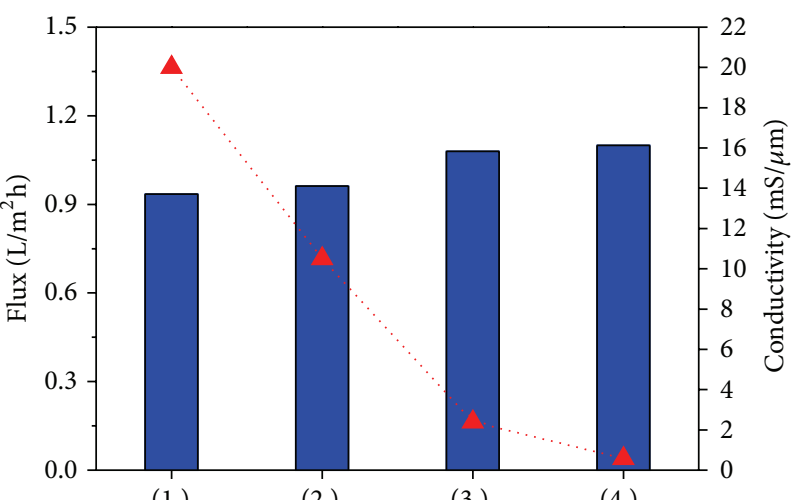

(1.)

(2.)

(3.)

(4.) $\square$ Flux

A. Conductivity

FIGURE 13: Circulated filtration of seawater using (a) PIP- and (b) MPD-based membranes.

a higher amount of salt ions. As a result, $98.9 \%$ of the salt ions were retained from the original seawater. The results of the ion-exchange chromatography analysis of the original and obtained permeate water matched the conductivity values.

The thin film nanofibrous composite membranes exhibited high mechanical properties and resisted an applied pressure of 4.8 bar in all of the filtration experiments. Primary results indicated that electrospun nanofibres are promising candidates for use as new high-performance nanofiltration membranes due to their high flux and ion rejection.

\section{Competing Interests}

The authors declare that they have no competing interests.

\section{Acknowledgments}

The results of this Project no. LO1201 were obtained through the financial support of the Ministry of Education, Youth and Sports in the framework of the targeted support of the "National Programme for Sustainability I and the OPR\&DI Project Centre for Nanomaterials, Advanced Technologies and Innovation CZ.1.05/2.1.00/01.0005." Special thanks are due to the University of Essen, Chemical Department, for their great help.

\section{References}

[1] H. Ettouney and M. Wilf, "Commercial desalination technologies," in Seawater Desalination: Conventional and Renewable Energy Processes, G. Micale, L. Rizzuti, and A. Cipollina, Eds., pp. 77-107, Springer, Berlin, Germany, 2009.

[2] J. Ribeiro, Desalination Technology: Survey and Prospects, IPTS, 1996.

[3] M. M. A. Shirazi, A. Kargari, and M. J. A. Shirazi, "Direct contact membrane distillation for seawater desalination," Desalination and Water Treatment, vol. 49, no. 1-3, pp. 368-375, 2012.
[4] L. M. Camacho, L. Dumée, J. Zhang et al., "Advances in membrane distillation for water desalination and purification applications," Water, vol. 5, no. 1, pp. 94-196, 2013.

[5] A. L. Ahmad, B. S. Ooi, A. W. Mohammad, and J. P. Choudhury, "Development of a highly hydrophilic nanofiltration membrane for desalination and water treatment," Desalination, vol. 168, no. 1-3, pp. 215-221, 2004.

[6] L. F. Greenlee, D. F. Lawler, B. D. Freeman, B. Marrot, and P. Moulin, "Reverse osmosis desalination: water sources, technology, and today's challenges," Water Research, vol. 43, no. 9, pp. 2317-2348, 2009.

[7] X. Lu, X. Bian, and L. Shi, "Preparation and characterization of NF composite membrane," Journal of Membrane Science, vol. 210, no. 1, pp. 3-11, 2002.

[8] A. I. Schäfer, A. G. Fane, and T. D. Waite, Nanofiltration: Principles and Applications, Elsevier Advanced Technology, Oxford, UK, 2005.

[9] E. L. Wittbecker and P. W. Morgan, "Interfacial polycondensation. I.," Journal of Polymer Science Part A: Polymer Chemistry, vol. 40, no. 137, pp. 289-297, 1959.

[10] R. J. Petersen, "Composite reverse osmosis and nanofiltration membranes," Journal of Membrane Science, vol. 83, no. 1, pp. 81150, 1993.

[11] J. E. Cadotte, "Interfacially synthesized reverse osmosis membrane," US Patents, 1981.

[12] J. E. Cadotte, R. J. Petersen, R. E. Larson, and E. E. Erickson, "A new thin-film composite seawater reverse osmosis membrane," Desalination, vol. 32, no. C, pp. 25-31, 1980.

[13] B. Yalcinkaya and F. Cengiz-Callioglu, "The roller electrospinning of poly(vinyl alcohol) nanofibers," in Proceedings of the 3rd Edition of the International Conference on Intelligent Textiles \& Mass Customisation (ITMC '11), p. 109, Casablanca, Morocco, October 2011.

[14] F. Yener and B. Yalcinkaya, "Electrospinning of polyvinyl butyral in different solvents," e-Polymers, vol. 13, no. 1, pp. 229242, 2013.

[15] K. Yoon, K. Kim, X. Wang, D. Fang, B. S. Hsiao, and B. Chu, "High flux ultrafiltration membranes based on electrospun 
nanofibrous PAN scaffolds and chitosan coating," Polymer, vol. 47, no. 7, pp. 2434-2441, 2006.

[16] L. Yung, H. Ma, X. Wang et al., "Fabrication of thin-film nanofibrous composite membranes by interfacial polymerization using ionic liquids as additives," Journal of Membrane Science, vol. 365, no. 1-2, pp. 52-58, 2010.

[17] N.-N. Bui, M. L. Lind, E. M. V. Hoek, and J. R. McCutcheon, "Electrospun nanofiber supported thin film composite membranes for engineered osmosis," Journal of Membrane Science, vol. 385-386, no. 1, pp. 10-19, 2011.

[18] Z. Fan, Z. Wang, M. Duan, J. Wang, and S. Wang, "Preparation and characterization of polyaniline/polysulfone nanocomposite ultrafiltration membrane," Journal of Membrane Science, vol. 310, no. 1-2, pp. 402-408, 2008.

[19] X. Wang, T.-M. Yeh, Z. Wang et al., "Nanofiltration membranes prepared by interfacial polymerization on thin-film nanofibrous composite scaffold," Polymer, vol. 55, no. 6, pp. 1358-1366, 2014.

[20] S.-S. Choi, Y. S. Lee, C. W. Joo, S. G. Lee, J. K. Park, and K.-S. Han, "Electrospun PVDF nanofiber web as polymer electrolyte or separator," Electrochimica Acta, vol. 50, no. 2-3, pp. 339-343, 2004.

[21] R. Sen, B. Zhao, D. Perea et al., "Preparation of single-walled carbon nanotube reinforced polystyrene and polyurethane nanofibers and membranes by electrospinning," Nano Letters, vol. 4, no. 3, pp. 459-464, 2004.

[22] X. Wang, K. Zhang, M. Zhu, B. S. Hsiao, and B. Chu, "Enhanced mechanical performance of self-bundled electrospun fiber yarns via post-treatments," Macromolecular Rapid Communications, vol. 29, no. 10, pp. 826-831, 2008.

[23] L. Huang, J. T. Arena, S. S. Manickam, X. Jiang, B. G. Willis, and J. R. McCutcheon, "Improved mechanical properties and hydrophilicity of electrospun nanofiber membranes for filtration applications by dopamine modification," Journal of Membrane Science, vol. 460, pp. 241-249, 2014.

[24] L. Huang, S. S. Manickam, and J. R. McCutcheon, "Increasing strength of electrospun nanofiber membranes for water filtration using solvent vapor," Journal of Membrane Science, vol. 436, pp. 213-220, 2013.

[25] K. Yoon, B. S. Hsiao, and B. Chu, "Formation of functional polyethersulfone electrospun membrane for water purification by mixed solvent and oxidation processes," Polymer, vol. 50, no. 13, pp. 2893-2899, 2009.

[26] S. Kaur, R. Barhate, S. Sundarrajan, T. Matsuura, and S. Ramakrishna, "Hot pressing of electrospun membrane composite and its influence on separation performance on thin film composite nanofiltration membrane," Desalination, vol. 279, no. 1-3, pp. 201-209, 2011.

[27] X. Wang, D. Fang, K. Yoon, B. S. Hsiao, and B. Chu, "High performance ultrafiltration composite membranes based on poly(vinyl alcohol) hydrogel coating on crosslinked nanofibrous poly(vinyl alcohol) scaffold," Journal of Membrane Science, vol. 278, no. 1-2, pp. 261-268, 2006.

[28] S. Kaur, Z. Ma, R. Gopal, G. Singh, S. Ramakrishna, and T. Matsuura, "Plasma-induced graft copolymerization of poly(methacrylic acid) on electrospun poly(vinylidene fluoride) nanofiber membrane," Langmuir, vol. 23, no. 26, pp. 13085-13092, 2007.

[29] S. Kaur, D. Rana, T. Matsuura, S. Sundarrajan, and S. Ramakrishna, "Preparation and characterization of surface modified electrospun membranes for higher filtration flux," Journal of Membrane Science, vol. 390-391, pp. 235-242, 2012.
[30] S. Hermans, R. Bernstein, A. Volodin, and I. F. J. Vankelecom, "Study of synthesis parameters and active layer morphology of interfacially polymerized polyamide-polysulfone membranes," Reactive and Functional Polymers, vol. 86, pp. 199-208, 2015.

[31] Y. Mansourpanah, K. Alizadeh, S. S. Madaeni, A. Rahimpour, and H. Soltani Afarani, "Using different surfactants for changing the properties of poly(piperazineamide) TFC nanofiltration membranes," Desalination, vol. 271, no. 1-3, pp. 169-177, 2011.

[32] Y. Mansourpanah, S. S. Madaeni, and A. Rahimpour, "Fabrication and development of interfacial polymerized thin-film composite nanofiltration membrane using different surfactants in organic phase; study of morphology and performance," Journal of Membrane Science, vol. 343, no. 1-2, pp. 219-228, 2009.

[33] J. Guilbaud, A. Massé, F.-C. Wolff, and P. Jaouen, "Seawater pretreatment by dead-end micro and ultrafiltration in pressuredriven inside feed," Desalination and Water Treatment, vol. 51, no. 1-3, pp. 416-422, 2013.

[34] S. C. J. M. van Hoof, J. G. Minnery, and B. Mack, "Dead-end ultrafiltration as alternative pre-treatment to reverse osmosis in seawater desalination: a case study," Desalination, vol. 139, no. 1-3, pp. 161-168, 2001.

[35] O. Jirsak, F. Sanetrnik, D. Lukas, V. Kotek, L. Martinova, and J. Chaloupek, "Method of nanofibres production from a polymer solution using electrostatic spinning and a device for carrying out the method," US Patents, 2005.

[36] J. K. Lin, M. R. Ladisch, J. A. Patterson, and C. H. Noller, "Determining pore size distribution in wet cellulose by measuring solute exclusion using a differential refractometer," Biotechnology and Bioengineering, vol. 29, no. 8, pp. 976-981, 1987.

[37] A. A. Manito Pereira, J. M. Timmer, and J. J. Keurentjes, "Swelling and compaction of nanofiltration membranes in a non-aqueous environment," Desalination, vol. 200, no. 1-3, pp. 381-382, 2006.

[38] K. M. Persson, V. Gekas, and G. Trägårdh, "Study of membrane compaction and its influence on ultrafiltration water permeability," Journal of Membrane Science, vol. 100, no. 2, pp. 155-162, 1995.

[39] R. K. McGovern, D. McConnon, and J. H. Lienhard V, "The effect of very high hydraulic pressure on the permeability and salt rejection of reverse osmosis membranes," in Proceedings of the IDA World Congress on Desalination and Water Reuse, International Desalination Association, San Diego, Calif, USA, 2015. 

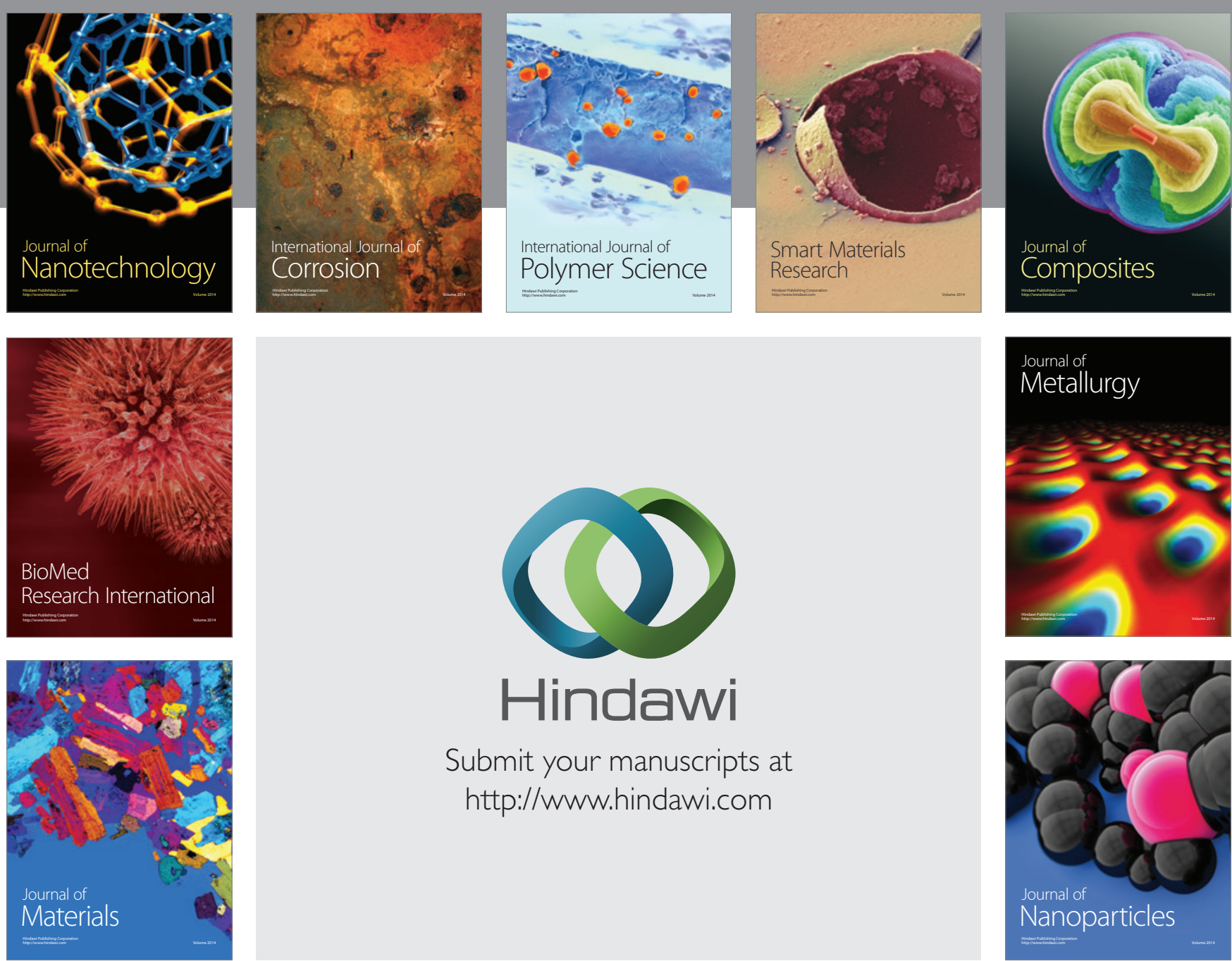

\section{Hindawi}

Submit your manuscripts at

http://www.hindawi.com

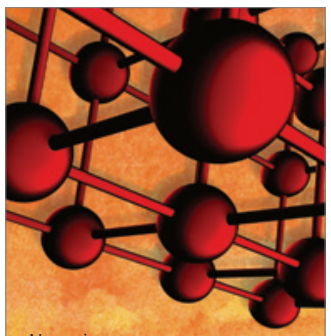

Materials Science and Engineering
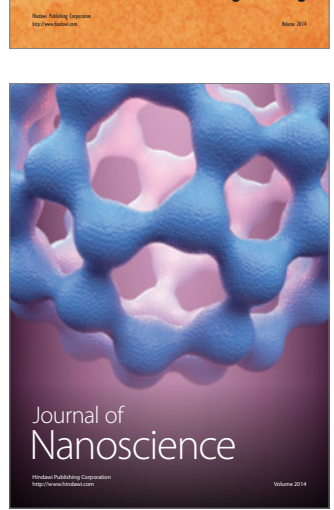
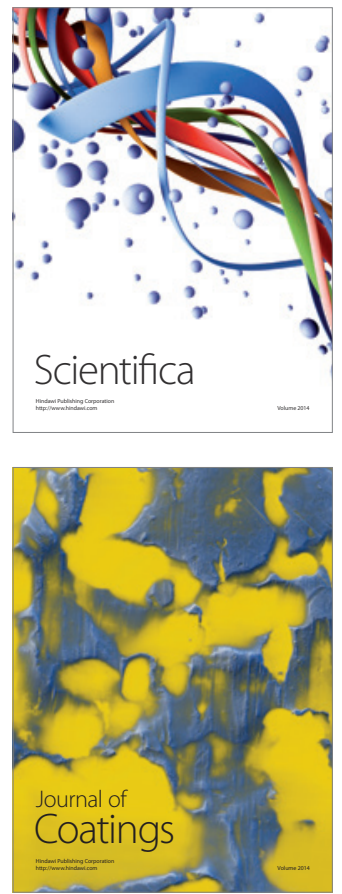
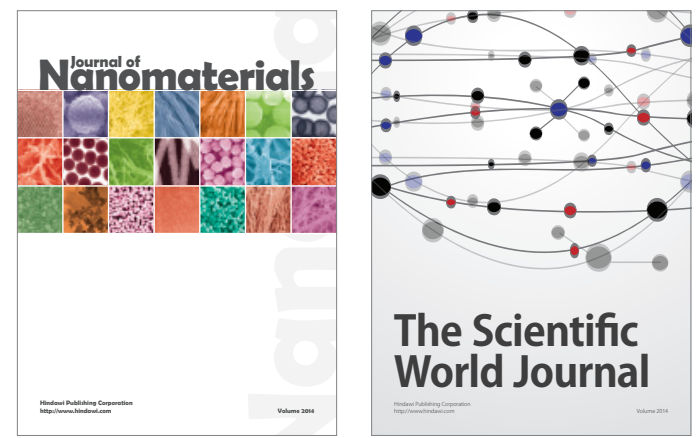

The Scientific World Journal
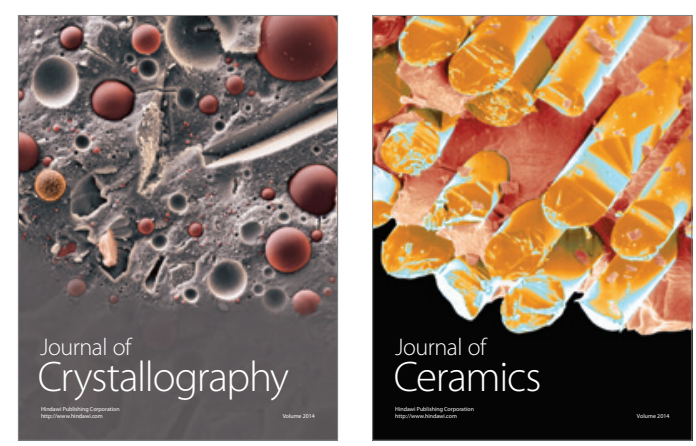
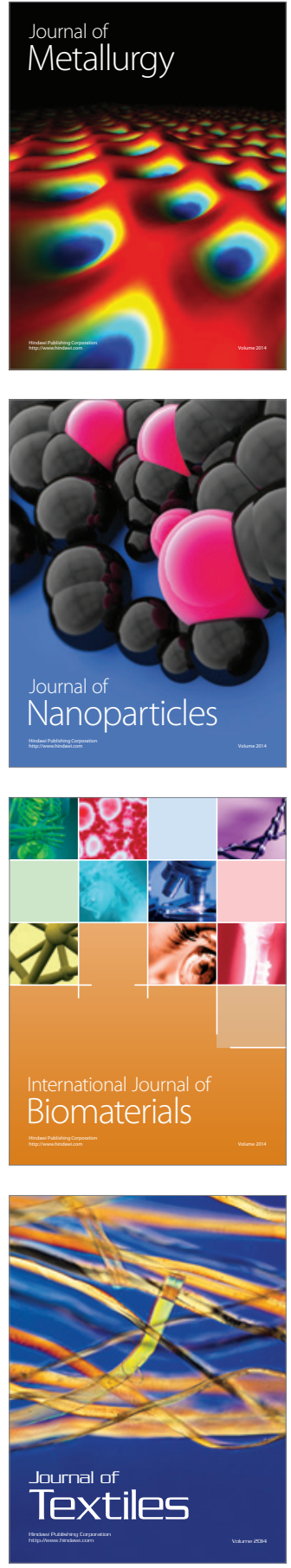